\title{
A practical approach for vaccinations including COVID-19 in autoimmune/autoinflammatory rheumatic diseases: a non-systematic review
}

\author{
Mehmet Soy $^{1,2}$ (D) Gökhan Keser $^{3}$ (D) Pamir Atagunduz ${ }^{4}$ (D) Melek Yalçin Mutlu $^{5,6}$ (D) Alper Gunduz $^{7}$ (D) \\ Gizem Koybaşi ${ }^{8}$ (D) Cemal Bes $^{9,10}$ (iD
}

Received: 9 February 2021 / Revised: 5 March 2021 / Accepted: 15 March 2021 / Published online: 22 March 2021

(C) International League of Associations for Rheumatology (ILAR) 2021

\begin{abstract}
The COVID-19 pandemic has occupied the world agenda since December 2019. With no effective treatment yet, vaccination seems to be the most effective method of prevention. Recently developed vaccines have been approved for emergency use only and are currently applied to large populations. Considering both the underlying pathogenic mechanisms of autoimmune/ autoinflammatory rheumatological diseases (AIIRDs) and the immunosuppressive drugs used in treatment, vaccination for COVID-19 deserves special attention in such patients. In this article, we aimed to give simple messages to the clinicians for COVID-19 vaccination in patients with AIIRDs based upon the current evidence regarding the use of other vaccines in this patient group. For this purpose, we conducted a "Pubmed search" using the following keywords: Influenza, Hepatitis B, Pneumococcal, and Shingles vaccines and the frequently used conventional and biologic disease-modifying antirheumatic drugs (DMARDs). Likewise, an additional search was performed for the COVID-19 immunization in patients with AIIRDs and considering such drugs. In summary, patients with AIIRDs should also be vaccinated against COVID-19, preferably when disease activity is under control and when there is no concurrent infection. Low-degree immunosuppression does not appear to decrease antibody responses to vaccines. Ideally, vaccinations should be done before the initiation of any biological DMARDs. Patients receiving rituximab should be vaccinated at least 4 weeks before or 6 months after treatment. Since tofacitinib may also reduce antibody responses, especially in combination with methotrexate, it may be appropriate to discontinue this drug before vaccination and to restart after 14 days of immunization.
\end{abstract}

Mehmet Soy

mhmtsoy@gmail.com

Gökhan Keser

agkkeser@gmail.com

Pamir Atagunduz

pamir.atagunduz@gmail.com

Melek Yalçin Mutlu

melekyalcinn@hotmail.com

Alper Gunduz

gunduzalper@gmail.com

Gizem Koybaşi

gizemkoybasi@gmail.com

Cemal Bes

cemalbes@hotmail.com

1 Altınbas University (previously Kemerbas University) Faculty of Medicine Department of Internal Medicine, Division of Rheumatology, Bahcelievler MedicalPark Hospital, Istanbul, Turkey
2 Present address: Altunizade Mah. Atif Bey sk. Gokdeniz Sitesi, E-3; Usküdar, Istanbul, Turkey

3 Ege University Faculty of Medicine Department of Internal Medicine, Division of Rheumatology, Bornova, Izmir, Turkey

4 Marmara University Faculty of Medicine Department of Internal Medicine, Division of Rheumatology, Istanbul, Turkey

5 University of Health Sciences, Basaksehir Cam and Sakura City Hospital, Basaksehir, Istanbul, Turkey

6 Department of Rheumatology, University of Health Sciences, Bakırköy Dr. Sadi Konuk Training and Research Hospital, İstanbul, Turkey

7 Şişli Hamidiye Etfal Training and Research Hospital, Department of Infectious Diseases, İstanbul, Turkey

8 Yedikule Chest Diseases and Chest Surgery Training and Research Hospital, İstanbul, Turkey

9 University of Health Sciences, Başakșehir Çam and Sakura City Hospital, Istanbul, Turkey

10 Department of Rheumatology, University of Health Sciences, Bakırköy Dr. Sadi Konuk Training and Research Hospital, İstanbul, Turkey 
Key points

- COVID-19 vaccinations should preferably be made during remission in patients with autoimmune/autoinflammatory rheumatological diseases.

- Low-degree immunosuppression may not interfere with antibody response to vaccines.

- Ideally, vaccinations should be made before the initiation of any biological DMARDs.

- Timing of vaccination is especially important in the case of rituximab.

Keywords Autoimmune/autoinflammatory rheumatological diseases $\cdot$ COVID-19 $\cdot$ DMARDs $\cdot$ Rituximab $\cdot$ Vaccine

\section{Introduction}

\section{SARS-CoV-2 and COVID-19 outbreak}

COVID-19, the acute illness caused by the severe acute respiratory syndrome coronavirus-2 (SARS-CoV-2), was first reported in Wuhan, Hubei, China, in December 2019 and declared as a global pandemic on 11 March 2020 [1].

Highly contagious SARS-CoV-2 is believed to spread mainly through respiratory droplets and close contact [2]. The beta coronavirus SARS-CoV-2 has an envelope and a single positive-stranded RNA and is notable for having the largest genome structure among RNA viruses. These characteristics allow the SARS-CoV to replicate using its viral genome as a template, without being integrated into the host genome [3]. In the replication stage, structural and nonstructural proteins are encoded. The novel coronavirus has four main structural proteins including the spike (S), membrane, envelope, and nucleocapsid proteins. The $\mathrm{S}$ protein, which gives the typical shape of the virus, contains a special binding site that allows the virus to attach to the host cell. In the host cell, the target of the virus is the angiotensin-converting enzyme-2 (ACE-2) receptor located in many organs and systems including the heart, lungs, kidneys, and gastrointestinal tract $[4,5]$. Severe clinical course and death are seen especially in patients with high-risk factors such as older age; tobacco use; and comorbidities including hypertension, diabetes mellitus, cardiac disease, chronic lung disease, cerebrovascular disease, chronic kidney disease, immunosuppression, and cancer [6,7].

\section{Attempts for vaccination against COVID-19}

Since a suitable treatment for COVID-19 has not been developed yet, and expecting the only occurrence of herd immunity in the population is not an ideal solution, developing suitable vaccines is of paramount importance. As of December 2020, there were 60 vaccines used in clinical trials and 172 vaccines in progress, which were registered by the World Health Organization (WHO) [8]. Some vaccines have already been approved by the Food and Drug Administration (FDA) for urgent application, and vaccination of the general population has started in many countries $[9,10]$.

\section{Concerns for vaccination in patients with autoimmune/autoinflammatory rheumatic diseases}

Considering that at least $1 \%$ of the population has an autoimmune rheumatic disease [11], and just as many might have an autoinflammatory disease, the issues of both safety and efficacy of vaccination in patients with autoimmune/ autoinflammatory rheumatic diseases (AIIRDs) are questioned. Considering both the pathogenetic mechanisms of these diseases and the immunosuppressive drugs used for these patients, some precautions may need to be taken before vaccination. Since some vaccine technologies will be applied for the first time and the doctors do not have sufficient experience and observation with these vaccines, there is an imminent rise of several questions about the vaccination of patients with AIIRDs. Although the initial phase of COVID-19 vaccine studies was promising, it should be noted that patients with AIIRDs and/or those taking immunosuppressive drugs were excluded from these studies [12-14]. Recently, the Centers for Disease Control (CDC) reported that patients with an underlying autoimmune disease might be vaccinated with the mRNA vaccines but also recommended close follow-up for these subgroups of patients after vaccination [15].

In this non-systematic review, we aimed to summarize the use of vaccines in patients with AIIRDs, with regard to efficacy and safety issues, and possible interactions with the antirheumatic/immunosuppressive drugs used. We aimed to cover the key vaccines as proposed by ACR/EULAR, including seasonal influenza, pneumococcal, shingles, HBV vaccines, and also the new COVID-19 vaccines, with regard to their optimal use for the best efficacy and preventive measures for lowering possible side effects.

\section{Methods}

The four key vaccines (influenza, hepatitis B, pneumococcal, and shingles vaccines), and frequently used biologic and nonbiologic disease-modifying antirheumatic drugs (DMARDs) and corticosteroids, were used as keywords. PubMed was searched from 20 December 2020 to 12 January 2021; articles of the last 20 years have been included 
Fig. 1 Literature search and number of references identified at each stage*: the articles on leflunomide, abatacept, and tofacitinib are not shown here because they have been used under other titles or because they are very few. Also, recently published ACR recommendations are included as a reference
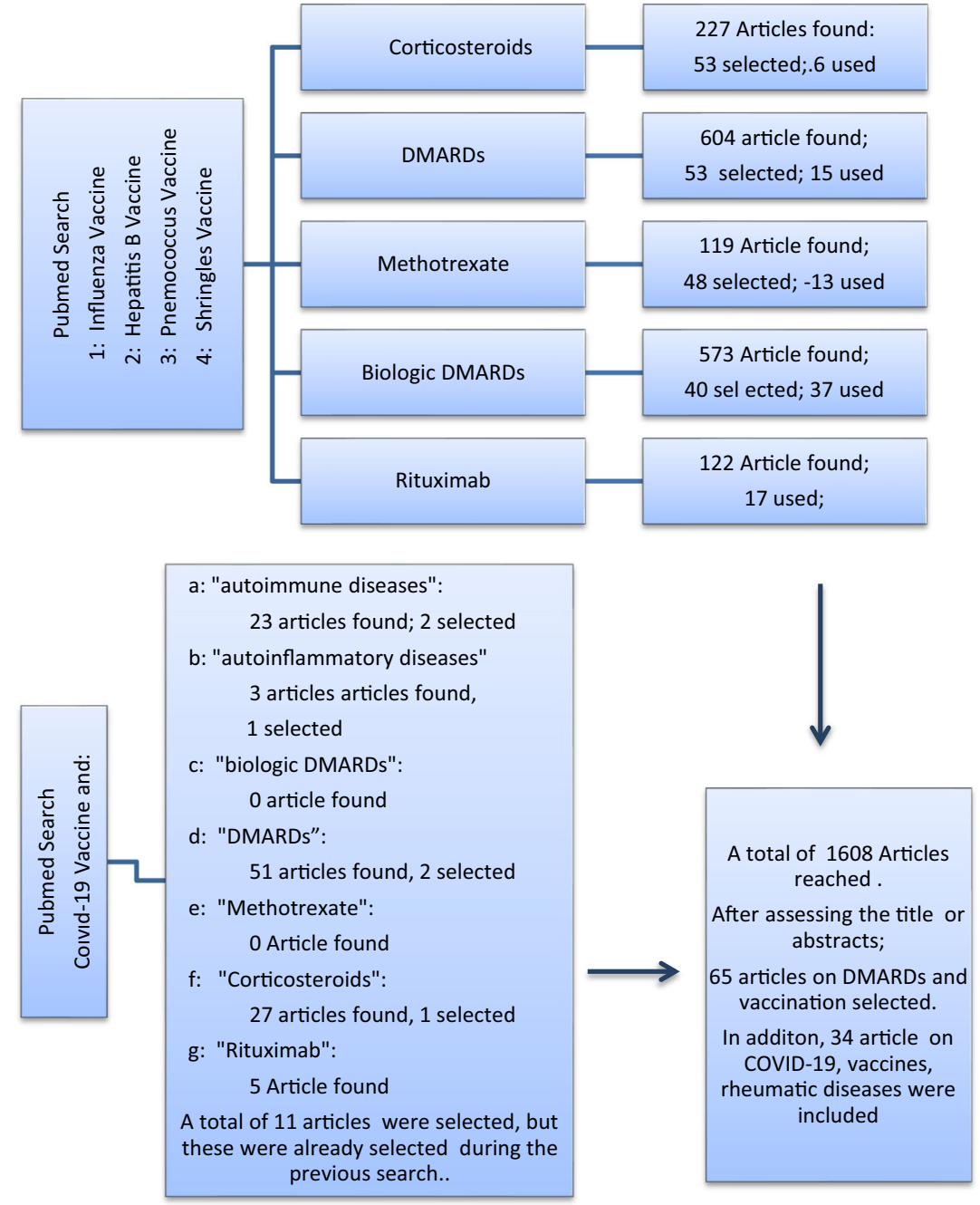

in the study. Likewise, an additional search was performed for the COVID-19 immunization in patients on biologic and nonbiologic DMARDs. Original data in all studies (including case reports and case series) published in the English language in peer-reviewed journals were included in the review.

The PubMed search, after eliminating duplicates reached by different keywords, revealed a total of 1608 articles. After reading the title and/or abstracts, 166 articles were selected on DMARDs and vaccines. The articles with similar topics and poor designation were eliminated; and finally, a total of 88 articles were used: 23 out of 88 which were shared references. Also, recently published ACR recommendations are included as a reference. In addition to these 66 references, 34 key references for vaccines, COVID-19, and rheumatic diseases were used. The manuscript selection method is outlined as a flow diagram in Fig. 1.

The results of our search were outlined as follows: we initially reviewed the general features of vaccines and their side effects and then concentrated on new vaccines developed against COVID-19. Then we tried to discuss whether vaccines may trigger autoimmunity in predisposed individuals and may exacerbate autoimmunity in patients with pre-existing autoimmune diseases. Finally, we tried to discuss the available data for the effect of the vaccines in patients with AIIRDs receiving $\mathrm{CS}$ and various nonbiologic and/or biologic DMARDs.

\section{General information about vaccines}

Vaccines prevent infections by inducing or enhancing protective immunity. The capacity of vaccines to induce humoral and cellular immunity is defined as "immunogenicity." Efficacy is the vaccine's capacity to prevent infection. For some diseases, immunogenicity correlates with efficacy but not for others. Safety is defined as not having serious side effects related to vaccination or not aggravating the underlying disease [16].

The vaccine against COVID-19 involved in clinical trials has diverse compositions: from traditional whole-pathogen vaccines to various new-generation vaccines. Traditional whole-pathogen vaccines consist of live-attenuated vaccines (live pathogens with reduced virulence) and inactivated 
vaccines (thermally or chemically inactivated pathogens). Liveattenuated vaccines introduce a mild infection that resembles the real infection, leading to a strong immune response, and the immunological memory can last for years [17].

The inactivated vaccines are safer as live pathogens are not involved, but they can be lower in immunogenicity and often require multiple doses to establish immune memory. The new-generation vaccines, including recombinant protein vaccines and vector-based vaccines, only incorporate a specific antigen or antigens from the pathogen, instead of the whole pathogen, giving a better safety profile.

Based on the carrier of the antigen, the new-generation vaccines for COVID-19 can be classified into recombinant protein-based vaccines and vector-based vaccines, e.g., messenger RNA (mRNA), plasmid DNA, viral vector-based, and nonpathogenic bacterial vector-based vaccines. The recombinant protein vaccine uses a part of the whole protein or a protein fragment such as the RBD or fusion of RBD with a carrier protein as the antigen. For SARS-CoV, it was shown that animals immunized with recombinant protein vaccine candidates can produce neutralizing antibodies [17].

In viral vector-based vaccines, the antigen is cloned into a viral vector that cannot reproduce. Common vectors include lentivirus, adenovirus, and adeno-associated virus. The viral vector imitates the viral infection disease state and therefore can produce stronger cellular immune responses as compared to the recombinant protein vaccines $[17,18]$.

However, the inactivated virus and recombinant protein antigen are often weakly immunogenic and require an adjuvant to boost the immunogenicity. Viral vector-based vaccines and bacterial vector-based vaccines do not require adjuvants. In the COVID-19 vaccine development race, the inactivated COVID-19 vaccine candidate from Sinovac uses $\mathrm{Al}(\mathrm{OH}) 3$ as the adjuvant [19].

The mRNA vaccine is the newest generation of vaccines in which all components can be produced via chemical synthesis. Since antigen expression from mRNA is a transient process, the risk of host DNA integration is negligible. There is poor apparent transfection effectiveness of naturally occurring mRNA molecules. Therefore, lipid nanoparticles (LNPs) are often used to incorporate the mRNA molecules for transfection purposes. A typical LNP formulation consists of an RNA condensing lipid to form a complex with the mRNA molecule, helper lipids to provide the structural rigidity, and lipidized polymer coating to modify the surface properties of the particles. Once phagocytosed by a cell, the mRNA vaccine temporarily induces the cell to produce the antigen protein coded by the mRNA. Therefore, the RNA condensing lipid is the key component of this platform. Moderna and Pfizer Biontech's COVID-19 vaccines are LNPencapsulated mRNA vaccines that encode the $\mathrm{S}$ protein, given in two doses by intramuscular injections [20] The FDA has approved those vaccines for emergency use $[9,10]$. These vaccines have been widely used in the USA and the European Union.
Among the risks posed with COVID-19 vaccine development is whether immune responses could enhance SARS$\mathrm{CoV}-2$ acquisition or make the disease worse when infection occurs after vaccination [20, 21]. Fortunately, no such side effect has been reported with COVID-19 vaccines to date. However, allergic reactions are reported more frequently than conventional vaccines. Fortunately, edema and thrombus formation, which are potential risks for mRNA vaccines, has not been reported yet. It is too early to comment on the risk of autoimmune disease triggering by these vaccines [22].

\section{May vaccines and their adjuvants trigger autoimmunity?}

Not only the vaccine itself but also the adjuvants included in vaccines may trigger autoimmunity [23]. Aluminum salts (alum) are used as an adjuvant in $80 \%$ of commercial human vaccines. When injected, the alum activates the NLRP3 inflammasome, followed by the release of proinflammatory cytokines including IL-1 $\beta$, IL-18, and IL-33. Alum recruits monocytes to the site of injection; these monocytes transfer to the draining lymph nodes and differentiate into dendritic cells (DCs) expressing CD11c and MHC class II molecules. These monocytic DC precursor cells are responsible for priming naive $\mathrm{CD}^{+} \mathrm{T}$ cells. The release of IL- $1 \beta$ contributes to Th2 $\mathrm{CD}^{+}{ }^{+}$-cell differentiation, which mediates the differentiation of B cells that secrete IgG1 and IgE [18-20].

However, it should be emphasized that although there are some case reports or case series of vaccine-induced autoimmune diseases in the literature, a clear-cut and significant risk of vaccine-induced autoimmunity has not been shown in any clinical or epidemiological study. Recently, a new syndrome called "autoimmune/inflammatory syndrome induced by adjuvants" (ASIA) was described [24]. Watad et al. reported that $39.7 \%$ of 300 ASIA cases had a prior vaccination history [25]. Considering the other adjuvants such as metal and silicone implants, $76.7 \%$ of cases had a history of encountering an adjuvant in the last 10 years. HBV, HPV, and influenza vaccines were the most frequently reported vaccines, while unclassified connective tissue disease was the most frequently reported autoimmune clinical picture. Wang et al. performed a systemic review and meta-analysis of 25 observational studies, 12 on the association between vaccinations and SLE and 13 on the association between vaccinations and RA risk. The pooled findings suggested that vaccinations significantly increased both the risks of SLE and RA [26]. However, the interpretation of these findings should be made cautiously. Among all people with SLE or RA, we cannot say for whom vaccine has had a causal role; we can only say that there are some patients in whom vaccination has contributed negatively to the development of the disease [27]. 
An mRNA molecule has intrinsic immunogenicity. For mRNA vaccines, proinflammatory responses may be induced by the molecules themselves and delivery vehicles like LNPs. The chemical changes in the mRNA molecules can alter their proinflammatory behavior, but the delivery vehicles and the mRNAs themselves can also create unnecessary proinflammatory responses $[19,28]$. Some mRNA-based vaccine platforms have the potential to cause powerful type I interferon responses, which have been associated with both inflammation and autoimmunity. mRNA may play a role as an adjuvant also and trigger the immune system. Furthermore, extracellular naked mRNA may increase the permeability of tightly packed epithelial cells and trigger thrombus formation [22]. However, since mRNA vaccines are not widely used, their clinical significance is not yet known. Those with autoimmune diseases or those with high familial burden should be closely monitored after mRNA vaccines.

On the other hand, before claiming that a vaccine induced autoimmune disease, one should follow-up the steps offered by WHO about interpreting adverse events of vaccines. Firstly, the association of a purported autoimmune event with the administration of a vaccine should be consistent. In other words, it should be observed by different investigators, irrespective of the method of investigation, and the association should be strong in an epidemiological sense. The association should also be distinctive, and the adverse event should be linked uniquely or specifically to the vaccine concerned; other possibilities should be excluded. There should also be a clear temporal relationship between the vaccine and the autoimmune event. However, defining an exact period for autoimmunity to rule out adverse effects of the vaccine is difficult [29, 24].

\section{Do vaccines exacerbate autoimmunity in patients with autoimmune diseases?}

As long as those non-live vaccines including influenza, pneumococcal, tetanus toxoid, hepatitis B virus (HBV), hepatitis A virus (HAV), and human papillomavirus (HPV) vaccines are administered in the quiescent phases of AIIRDs, they are generally accepted as safe and do not exacerbate pre-existing autoimmunity. The origin of the tendency to give the vaccines in the quiescent phase of AIIRDs is an expert opinion, and EULAR recommendations are also consistent with this statement. Although there are several case reports and series on the onset and exacerbation of SLE after HPV vaccination [30-32] and an up to $30 \%$ rate of flare in vaccinated patients with SLE in an open study, other large-scale studies have not shown an increase in the incidence of autoimmune diseases among young females vaccinated against HPV. Besides, a casecontrol study on HPV vaccination in SLE patients showed a similar rate of flares in both vaccinated and unvaccinated groups [33]. Therefore, it is a common trend to make vaccinations in patients with AIIRDs based upon an acceptable benefit-risk ratio.

In brief, it is recommended that vaccines are not administered during the clinical or serologically active period of the disease [34], and similar recommendations will also apply for COVID-19 vaccines.

\section{Antirheumatic drugs and vaccines}

Patients with AIIRDs are at a higher risk of infection frequency than healthy people. This is due to the complex multifactorial interactions among innate immune dysfunction, disease activity, immunosuppression due to drugs, and the presence of various comorbidities. Antirheumatic immunosuppressive agents include, but not limited to, corticosteroids (CS), methotrexate (MTX), leflunomide, tumor necrosis factor inhibitors (TNFi), anti-IL-6R tocilizumab (TCZ), anti-CD20 rituximab (RTX), anti-costimulatory molecule blocker abatacept (ABA), IL-1 inhibitors, and small molecules including tofacitinib (TOFA). While some of these drugs may cause low-degree immunosuppression, depending on their doses, others may develop higher and longer immunosuppression. Low degree of immunosuppression usually occurs with doses of prednisone or equivalents $<20 \mathrm{mg}$ /day, MTX doses $\leq 0.4$ $\mathrm{mg} / \mathrm{kg} /$ week, and azathioprine doses $\leq 3.0 \mathrm{mg} / \mathrm{kg} /$ day [35]. The CDC advises that the vaccines can be used safely in such patients [35]. Hagihara et al. reported that azathioprine combination with infliximab (IFX) may reduce trivalent influenza vaccine antibody titers [36]. Therefore, one should be more careful with such combinations.

EULAR released an updated recommendation set for vaccination for patients with AIIRDs in 2019. According to these recommendations, while non-live vaccines (such as hepatitis A, rabies, polio, and influenza shot) can be safely administered to such patients regardless of the treatment being taken, care should be taken for live-attenuated vaccines. For most patients with AIIRDs, influenza and pneumococcal vaccines should be recommended. On the other hand, tetanus toxoid and human papillomavirus vaccinations should be performed in AIIRDs patients as recommended for the general population. Hepatitis A, hepatitis B, and herpes zoster vaccines should be administered only to patients at risk. Immunocompetent family members of patients with AIIRDs should be vaccinated according to national guidelines, except for the oral poliomyelitis vaccine [34]. As a general rule, live vaccines are not recommended for immunosuppressed individuals.

\section{Vaccines and corticosteroid treatment}

CS alone or in combination with other immunosuppressive agents are used for the treatment of patients with AIIRDs. In 
the case of vaccination, the doses of both CS and the other immunosuppressive drugs should be considered. In maintenance treatment, CS drugs are often used in low doses but sometimes it may be necessary to use at high doses of 1 $\mathrm{mg} / \mathrm{kg} /$ day or higher doses as pulse therapies for a short time. We do not know whether the CS treatment will change the immune response following COVID-19 vaccines. We can make some comments based upon the data regarding the effect of CS doses on other currently available vaccines being used routinely.

Fischer et al. showed that the pneumococcal vaccine was associated with insufficient antibody response when prednisolone doses higher than $10 \mathrm{mg}$ daily were used. PPV vaccine was well tolerated in this group of patients and was shown that it did not affect disease activity [37]. Similar results have been reported in different studies [38, 39]. CDC advises that the shingles vaccine can be used safely with low-degree immunosuppression and in those receiving intra-articular, bursal, or tendon CS injections [35]. Also, CDC allows administration of the herpes zoster vaccine at least 14 days before an expected immunosuppressive therapy [35].

\section{Implications for COVID-19 vaccines and CS treatment}

COVID-19 vaccine antibody response may be altered in patients receiving prednisone (or equivalent) doses higher than $10 \mathrm{mg} /$ day. Therefore, the COVID-19 vaccine should be given during the inactive period of the disease while the patient is on lower doses of CS.

\section{Vaccines and treatment with nonbiological DMARDs}

The nonbiological DMARDs, except for MTX, do not appear to have a significant effect on influenza vaccine efficacy $[38,40]$ Some authors suggest that any patient using an immunosuppressive drug other than RTX should be vaccinated each fall before the arrival of the influenza season regardless of their current immunosuppressive regimen [39]. But, if patients on biologic therapy are to be vaccinated for shingles, it is recommended to wait at least 1 month after discontinuation of biologics. Another option is vaccinating 2 to 4 weeks before starting a biologic. These time intervals are recommended broadly for all immunosuppressive medications; however, since the duration of immunomodulatory effects varies greatly among biologics, this recommendation should be considered carefully in patients taking biologics with longer effect duration [38].

Low-dose weekly MTX is the most widely used drug for patients with AIIRDs, especially RA. It may be used alone or more frequently in combination with other agents including low-dose CS or biologics [41]. For this reason, the effect of the other drugs on vaccines should also be considered. The results of clinical studies evaluating the sole effect of MTX on influenza vaccine immunogenicity are somewhat conflicting. Although overall antibody titers were lower, most patients vaccinated while using MTX generally achieved titers sufficient to protect against influenza infection [38, 39, 42-46]. Although some studies recommend skipping MTX doses 2 weeks before and 2 weeks after the influenza vaccine in RA patients, some experts do not accept this recommendation because of the risk of RA exacerbation [47]. Metha et al. claimed that skipping one or two doses of MTX after vaccination would not affect both the disease activity and effectiveness of the influenza vaccine. They stated that this could also apply to COVID-19 [48]. Fischer et al. reported that MTX treatment was not associated with poor response to PPV in a small group of patients with RA. But in combination with TNFi, they observed poor responses [37].

There is no particular warning for leflunomide (LEF), and the rules defined for other classic DMARDs also apply to LEF $[37,38]$. However, since LEF can remain in the body in the long term, it will not be meaningful to stop it for a short period. Therefore, we recommend that patients taking LEF may be vaccinated without stopping the medication.

\section{Implications for COVID-19 vaccines and nonbiological DMARDs}

Skipping 1-2 doses of MTX after COVID-19 vaccination seems appropriate for both the effectiveness of the vaccine and avoiding disease exacerbation.

Vaccines and tumor necrosis factor- $a$ inhibitor agents

Although controversial reports exist in literature about the effect of TNFi agents on influenza vaccination response [49, 50-52], the meta-analysis performed by Subesinghe et al. showed that TNFi therapy did not impair influenza vaccine responses [44, 53]. They pooled the data of 263 RA patients and 499 healthy controls from seven studies and reported that TNFi exposure was not associated with reduced SP responses to H1N1, H3N2, or B strain. There are also two studies reporting on 273 subjects (141 RA and $132 \mathrm{HC}$ ) assessing $6 \mathrm{~B}$ and $23 \mathrm{~F}$ pneumococcal serotype responses with TNFi exposure $[54,45]$. Both of these studies showed that TNFi exposure had no significant detriment to vaccine response compared to healthy controls [55].

\section{Vaccines and IL-17 inhibitors}

There are a few, albeit limited, studies evaluating the effect of vaccination and its complications in patients using secukinumab [56-58]. The effect of inactive vaccines, including the humoral immune response, was not found to be different from the healthy population. Additionally, in a study conducted with ixekizumab, another interleukin-17A antagonist, 
it was shown that the humoral response to inactive vaccines, including tetanus and pneumococcal vaccines, was not different when compared to healthy people [59]. If vaccination is to be made, this should preferably be done before starting secukinumab therapy. Live vaccines (such as herpes zoster, and polio) are not recommended for use in patients using immunosuppressives, which is also true for patients using secukinumab [34].

\section{Vaccines and tocilizumab}

TCZ is a humanized monoclonal IL-6 receptor blocker and is generally used for the treatment of diseases such as rheumatoid arthritis and large vessel vasculitis. It is also one of the main choices of cytokine storm treatment that may develop in the course of COVID-19 [60]. Mori et al. showed that TCZ treatment did not prevent the development of antibodies against the influenza vaccine in RA patients [61]. Recently, in another study evaluating the humoral immune response of the polysaccharide pneumococcal vaccine in RA patients receiving TCZ, no difference was observed between TCZ recipients and the control groups $[62,63]$.

\section{Vaccines and abatacept treatment}

Vaccination during the use of abatacept does not appear to affect the antibody response [64].

\section{Vaccines and IL-1 inhibitors}

Patients with autoinflammatory diseases potentially face lifelong immunosuppression, thus facing the dilemma of when vaccinations could be given [65]. An increased incidence of vaccine-preventable infections of influenza, pneumococci, human papillomavirus, and herpes zoster (HZ) was reported recently in adult patients with AIIRDs [66].

As a general rule, live-attenuated vaccines are not recommended for both pediatric and adult patients using IL-1 blocking agents[67-69]. A recent retrospective, multicenter survey evaluated the safety and efficacy of live-attenuated vaccines in patients using IL-1 or IL-6 blocking agents [70] and reported disease activation in some patients after vaccination. Discontinuation of IL-1 blockers before vaccination was seemingly the cause, and the authors concluded that the current data is inadequate to draw any conclusions about the safety of these vaccines in patients using IL-1 and physicians should balance the risk of infections versus the risk of disease flares and adverse events for each patient.

On the other hand, several studies confirmed the safety and efficacy of inactivated vaccines under IL-1 blocking therapy [71-74]. Quartier et al. reported that the antipneumococcal antibody response after 1 month was good, and the levels of postvaccination antibodies against five pneumococcal capsular polysaccharide serotypes were similar in patients under anakinra treatment compared to the placebo group [73]. Flares were not addressed in this study.

Canakinumab is safe and effective in controlling the disease activity after vaccination in CAPS patients [72, 75]. However, a recent study showed that CAPS patients treated with canakinumab reacted severely after pneumococcal vaccination [76].

The only study on the effectiveness of the hepatitis B vaccine in patients under immunosuppression included only a single patient treated with anakinra, and it is not possible to evaluate the effect of anakinra on hepatitis B vaccination [77].

In conclusion, the data on vaccination under immunosuppression of IL-1 blockade is scarce. Until the emergence of further data, general recommendations and risk-benefit ratio should be considered [78].

\section{Implications for COVID-19 vaccines and biological agents including TNFi, secukinumab, tocilizumab, IL-1 inhibitors, and abatacept}

Despite limited current data, drug-vaccine interactions seem to be unlikely. Vaccination just before the next scheduled dose and restarting biologics after at least 14 days thereafter could allow a window for antibody development. Patients should be followed closely for postvaccination side effects and disease exacerbations.

\section{Vaccines and rituximab treatment}

Anti-CD20 treatments affect the production of protective antibodies by vaccination via making B-cell depletion. This effect may persist for 6-10 months after RTX infusion [78-86]. Arad et al. reported that cellular immune response to influenza vaccination was preserved in RA patients treated with RTX. They also reported that a longer interval between RTX administration and influenza vaccination, and a higher B-cell count, correlated with a relatively improved antibody response [83]. However, Oren et al. could not confirm this observation [82]. Similar to influenza vaccination, the effect of RTX on humoral responses to pneumococcal vaccination is generally worse as expected [78, 87-89]. Bingham et al. compared and demonstrated that RTX-exposed RA patients showed a reduced response to vaccination for each of the twelve PPV23 serotypes tested [89]. Therefore, the time of vaccination is very critical for a patient receiving RTX. Based upon the wellknown B-cell depleting effect of RTX and the clinical observations and study results, any vaccination should be provided at least 4 weeks before or 6 months after the administration of RTX. If this is not achieved, vaccination should be performed at a time when immunoglobulin levels are at a normal level $[90,91]$. Otherwise, the potential for suboptimal response to the vaccine should be considered [34, 92-94]. 


\section{Implications for COVID-19 vaccines and RTX treatment}

The earlier warnings should also apply to COVID-19 patients.

\section{Vaccines and tofacitinib}

Because of interferon inhibition, in addition to other mechanisms, tofacitinib reduces antibody responses after vaccination, especially in combination with tofacitinib/methotrexate. For this reason, pretreatment vaccination or treatment interruption before vaccination is recommended [95]. If the patient is in remission, it may be appropriate to discontinue the drug before vaccination and to start again after 14 days.

\section{Discussion and conclusion}

As effective treatment against COVID-19 has not been developed yet, the importance of protection from infections and vaccination has been understood once again as COVID-19 has entered our lives. Numerous vaccination studies are conducted against COVID-19. Phase 3 studies of some of these vaccines were completed and approved for emergency use by the FDA or the countries' health authorities. These research and approval processes have been completed in a much shorter time compared to many vaccine and drug development processes that have been carried out so far. Approval of the vaccine without sufficient experience in terms of its effectiveness and possible side effects has raised questions about the safety and efficacy of these vaccines.

Pfizer/Biontech and Moderna vaccines are mRNA-based vaccines, and the first large population vaccination will be made. An increase in the frequency of allergic reactions has been reported with these vaccines. Although the median interval from vaccine receipt to symptom onset was reported as $13 \mathrm{~min}$ (range: $2-150 \mathrm{~min}$ ), 71\% developed within the first $15 \mathrm{~min}$ [96]. Due to the increased frequency of allergic reactions, longer follow-up of these patients should be recommended during the administration of these vaccines to AIIRDs patients.

AstraZeneca and Sinovac vaccines are also vaccines for which phase 3 studies have been conducted and large population application has begun [97]. The phase 3 results of the Sinovac vaccine have not yet been published as an article.

The EULAR and rheumatology associations of many countries have recommended vaccination of patients with AIIRDs, but there are no sufficient warnings about possible side effects and measures to be taken in terms of efficacy [98, 99].

Recently, ACR also prepared guidance and recommendations for the use of COVID-19 vaccines for patients with rheumatic diseases. As they also point out, it is clear that all of the current recommendations seem to be arbitrary and may change as new real-life and clinical trial data emerge. Since cyclophosphamide (CYP) is a more potent immunosuppressive drug compared to MTX and other routinely used agents, the possible negative impact on vaccination seems unavoidable. However, a gap of 1 week is recommended for most drugs including pulse CYP in the recently published ACR recommendations. On the other hand, according to CDC, 14 days are required for adequate antibody response after vaccination [35]. We believe that ACR underestimates the potential effects of drugs such as CYP and high-dose CS that could reduce the effectiveness of the vaccines. Despite the lack of sufficient data for CYP, we recommend more caution and believe that CYP and high doses of $\mathrm{CS}$ may require longer discontinuation periods, whenever possible, to permit an effective antibody response to vaccination [100].

In this article, we aimed to give some basic messages to the clinicians that may be considered during the period of COVID-19 vaccination for patients with AIIRDs. We mostly extrapolated from the previous data regarding frequently used vaccines and their interactions both with AIIRDs and the treatment agents used for such diseases.

Our take-home messages for the clinicians include:

1. Similar to the general population, patients with AIIRDs should also be vaccinated against COVID-19; however, vaccinations should be preferably made when disease activity is under control and when there is no concurrent infection.

2. Before vaccination, the immunosuppressive drugs that these patients were receiving should be carefully reviewed.

3. It should be kept in mind that low-degree immunosuppression does not appear to decrease antibody responses to vaccines.

4. Vaccination of patients receiving high-dose CS should be done when the daily CS dose falls below $10 \mathrm{mg} /$ day prednisolone or its equivalent.

5. In clinically stable patients, the scheduled dose of MTX before the vaccination and the subsequent weekly dose may be skipped. However, there seems to be no special and rational precaution for leflunomide.

6. Ideally, vaccination should be done before the initiation of any biological DMARDs. It appears that biologics including TNFi, TCZ, ABA, and IL-17 blockers have no impact on the effectiveness of vaccines; nevertheless, as the $\mathrm{CDC}$ recommends for other vaccines, a safety margin of 14 days before and after vaccination may be considered in clinically stable patients.

7. IL-1 blocker therapy does not appear to interfere with vaccination. Inactivated vaccines under IL-1 blocking therapy are safe and effective. However, these patients should be followed for disease exacerbations and side effects. 
8. The patients receiving RTX should be vaccinated at least 4 weeks before treatment or 6 months after treatment is received.

9. Tofacitinib may reduce antibody responses after vaccination, especially in combination with methotrexate. It may be appropriate to discontinue this drug before vaccination and to restart after 14 days of immunization.

10. Patients, who are more likely to have drug allergies such as patients with systemic lupus erythematosus, should be monitored for a longer period of time (up to $150 \mathrm{~min}$ ) after vaccination.

11. Even if vaccinated, these patients must continue to comply with the rules of using personal protective equipment, social distancing, and hygiene.

Availability of data and material Resource scanning was done in Pubmed with appropriate keywords. Original data in all studies (including case reports and case series) that addressed "the vaccines for COVID-19 and nonbiologic and biologic disease modifying antirheumatic drugs" published in the English language in peer-reviewed journals were included. The search algorithm for cited articles is given in Fig. 1.

\section{Author contribution}

As of December 20,2020, data were started to be collected by authors and turned into an article.

- Introduction and SARS-COV-2 and COVID-19 outbreak: Gizem Koybasi and Mehmet Soy MD

- Attempts for vaccination against COVID-19: Mehmet Soy, Gizem Koybasi, and Alper Gündüz

- Concerns for vaccination in patients with autoimmune/autoinflammatory rheumatic diseases: Alper Gündüz, Melek Yalçin Mutlu, Cemal Bes, Gokhan Keser, and Mehmet Soy

- General Information About Vaccines: Alper Gündüz

- May vaccines and their adjuvants trigger autoimmunity?: Gokhan Keser; Melek Yalçin Mutlu, and Cemal Bes

- Do vaccines exacerbate autoimmunity in patients with autoimmune diseases: Gokhan Keser

- Antirheumatic Drugs and Vaccines: Mehmet Soy, Gokhan Keser, Pamir Atagunguz, Melek Yalçin Mutlu, and Cemal Bes

The article is reviewed by Gokhan KESER (33.33\%), Pamir Atagunguz(33.33\%), and Mehmet Soy (33.33\%) and structured as the last version. The figure has been produced by Mehmet Soy and Pamir Atagunduz.

\section{Compliance with ethical standards}

Ethics approval Since it is a review article, we have no ethical approval, and we declared that all procedures performed in the present study were in accordance with the ethical standards of the institutional and/ or national research committee and with the 1964 Helsinki Declaration and its later amendments or comparable ethical standards.

Consent to participate All of the authors accepted the last version of the article and signed the author's disclosure.

Consent for publication All of the authors accepted the last version of the article for publication and signed the author's disclosure.

Disclosures None.
Code availability No code or software.

\section{References}

1. Kaswa R, Govender I (2020) Novel coronavirus pandemic: a clinical overview. S Afr Fam Pract (2004) 62(1):e1-e5. https://doi. org/10.4102/safp.v62i1.5123

2. Zhu N, Zhang D, Wang W, Li X, Yang B, Song J, Zhao X, Huang B, Shi W, Lu R, Niu P, Zhan F, Ma X, Wang D, Xu W, Wu G, Gao GF, Tan W, China Novel Coronavirus Investigating and Research Team (2020) A novel coronavirus from patients with pneumonia in China, 2019. N Engl J Med 382(8):727-733. https://doi.org/10.1056/NEJMoa2001017

3. Lu R, Zhao X, Li J, Niu P, Yang B, Wu H, Wang W, et al.(2020). Genomic characterisation and epidemiology of 2019 novel coronavirus: implications for virus origins and receptor binding. Lancet. 395(10224):565-574. https://doi.org/10.1016/S01406736(20)30251-8.

4. Zhou M, Zhang X, Qu J (2020) Coronavirus disease 2019 (COVID-19): a clinical update. Front Med 14(2):126-135. https://doi.org/10.1007/s11684-020-0767-8

5. Chen Y, Liu Q, Guo D (2020) Emerging coronaviruses: genome structure, replication, and pathogenesis. J Med Virol 92:418-423. https://doi.org/10.1002/jmv.25681

6. Zhou F, Yu T, Du R, Fan G, Liu Y, Liu Z, Xiang J, Wang Y, Song B, Gu X, Guan L, Wei Y, Li H, Wu X, Xu J, Tu S, Zhang Y, Chen $\mathrm{H}$, Cao B (2020) Clinical course and risk factors for mortality of adult inpatients with COVID-19 in Wuhan, China: a retrospective cohort study. Lancet 395(10229):1054-1062. https://doi.org/10. 1016/S0140-6736(20)30566-3

7. Varghese GM, John R, Manesh A, Karthik R, Abraham OC (2020) Clinical management of COVID-19. Indian J Med Res 151:401-410. https://doi.org/10.4103/ijmr.IJMR_957_20

8. World Health Organization. Draft landscape of COVID-19 candidate vaccines. https://www.who.int/publications/m/item/draftlandscape-of-covid-19-candidate-vaccines. Last accessed 29.12. 2020.

9. https://www.fda.gov/media/144412/download. Last accessed 04 . 01.2021

10. https://www.fda.gov/media/144636/download. Last accessed 04 . 01.2021

11. Broten L, Aviña-Zubieta JA, Lacaille D, Joseph L, Hanly JG, Lix L, O'Donnell S, Barnabe C, Fortin PR, Hudson M, Jean S, Peschken C, Edworthy SM, Svenson L, Pineau CA, Clarke AE, Smith M, Bélisle P, Badley EM, Bergeron L, Bernatsky S (2014) Systemic autoimmune rheumatic disease prevalence in Canada: updated analyses across 7 provinces. J Rheumatol 41(4):673679. https://doi.org/10.3899/jrheum.130667.

12. Kumar A, Quraishi MN, Segal JP, Raine T, Brookes MJ (2020) COVID-19 vaccinations in patients with inflammatory bowel disease. Lancet Gastroenterol Hepatol 5:965-966. https://doi.org/10. 1016/s2468-1253(20)30295-8.

13. Velikova T, Georgiev T (2021) SARS-CoV-2 vaccines and autoimmune diseases amidst the COVID-19 crisis. Rheumatol Int. https://doi.org/10.1007/s00296-021-04792-9

14. Rodríguez Y, Novelli L, Rojas M, De Santis M, Acosta-Ampudia Y, Monsalve DM, Ramírez-Santana C, Costanzo A, Ridgway WM, Ansari AA, Gershwin ME, Selmi C, Anaya JM (2020) Autoinflammatory and autoimmune conditions at the crossroad of COVID-19. J Autoimmun 114:102506. https://doi.org/10. 1016/j.jaut.2020.102506.

15. https://www.cdc.gov/coronavirus/2019-ncov/vaccines/ recommendations/underlying-conditions.html. Last accessed: 12 Jan 2021 
16. Plotkin S (2014) History of vaccination. Proc Natl Acad Sci U S A 111(34):12283-12287. https://doi.org/10.1073/pnas.1400472111

17. Kelly DF, Rappuoli R (2005) Reverse vaccinology and vaccines for serogroup B Neisseria meningitidis. Hot topics in infection and immunity in children II: Springer; $p$ 217-23

18. Zepp F (2010) Principles of vaccine design-lessons from nature. Vaccine (Basel) 28:C14-C24

19. Wang J, Peng Y, Xu H, Cui Z, Williams RO 3rd. (2020) The COVID-19 vaccine race: challenges and opportunities in vaccine formulation. AAPS PharmSciTech 21(6):1-12

20. Forni G, Mantovani A, COVID-19 Commission of Accademia Nazionale dei Lincei, Rome (2021) COVID-19 vaccines: where we stand and challenges ahead. Cell Death Differ 28(2):626-639. https://doi.org/10.1038/s41418-020-00720-9

21. Prü $\beta$ BM (2021) Current state of the first COVID-19 vaccines. Vaccines (Basel) 9(1):30

22. Pardi N, Hogan MJ, Porter FW, Weissman D (2018) mRNA vaccines - a new era in vaccinology. Nat Rev Drug Discov 17(4): 261-279. https://doi.org/10.1038/nrd.2017.243.

23. Segal Y, Shoenfeld Y (2018) Vaccine-induced autoimmunity: the role of molecular mimicry and immune crossreaction. Cell Mol Immunol 15:586-594. https://doi.org/10.1038/cmi.2017.151

24. uimarães LE, Baker B, Perricone C, Shoenfeld Y (2015) Vaccines, adjuvants and autoimmunity. Pharmacol Res 100:190-209. https://doi.org/10.1016/j.phrs.2015.08.003

25. Watad A, Quaresma M, Bragazzi NL, Cervera R, Tervaert JWC, Amital H, Shoenfeld Y (2018) The autoimmune/inflammatory syndrome induced by adjuvants (ASIA)/Shoenfeld's syndrome: descriptive analysis of 300 patients from the international ASIA syndrome registry. Clin Rheumatol 37(2):483-493. https://doi. org/10.1007/s10067-017-3748-9.

26. Wang B, Shao X, Wang D, Xu D, Zhang JA (2017) Vaccinations and risk of systemic lupus erythematosus and rheumatoid arthritis: a systematic review and meta-analysis. Autoimmun Rev 16(7): 756-765. https://doi.org/10.1016/j.autrev.2017.05.012.

27. Bellavite $\mathrm{P}$ (2020) Causality assessment of adverse events following immunization: the problem of multifactorial pathology. F1000Research 9:170. https://doi.org/10.12688/f1000research. 22600.2

28. https://vac-lshtm.shinyapps.io/ncov_vaccine_landscape/ last Accessed 21 January 2021.

29. Wraith DC, Goldman M, Lambert PH (2003) Vaccination and autoimmune disease: what is the evidence? Lancet 362(9396): 1659-1666. https://doi.org/10.1016/S0140-6736(03)14802-7

30. Soldevilla HF, Briones SF, Navarra SV (2012) Systemic lupus erythematosus following HPV immunization or infection? Lupus 21(2):158-161. https://doi.org/10.1177/0961203311429556

31. Baker B, Eça Guimarães L, Tomljenovic L, Agmon-Levin N, Shoenfeld Y (2015) The safety of human papilloma virusblockers and the risk of triggering autoimmune diseases. Expert Opin Drug Saf 14(9):1387-1394. https://doi.org/10.1517/ 14740338.2015.1073710

32. Segal Y, Calabrò M, Kanduc D, Shoenfeld Y (2017) Human papilloma virus and lupus: the virus, the vaccine and the disease. Curr Opin Rheumatol 29(4):331-342. https://doi.org/10.1097/BOR. 0000000000000398

33. Mok CC, Ho LY, Fong LS, To CH (2013) Immunogenicity and safety of a quadrivalent human papillomavirus vaccine in patients with systemic lupus erythematosus: a case-control study. Ann Rheum Dis 72(5):659-664. https://doi.org/10.1136/ annrheumdis-2012-201393

34. Furer, V., Rondaan, C., Heijstek, M.W., Agmon-Levin, N., Van Assen, S., Bijl, M., Breedveld, F.C., etal. (2020) 2019 update of EULAR recommendations for vaccination in adult patients with autoimmune inflammatory rheumatic diseases. Ann Rheum Dis 79, 39-52. https://doi.org/10.1136/annrheumdis-2019-215882.
35. Harpaz R, Ortega-Sanchez IR, Seward JF, Advisory Committee on Immunization Practices (ACIP) Centers for Disease Control and Prevention (CDC) (2008) Prevention of herpes zoster: recommendations of the Advisory Committee on Immunization Practices (ACIP). MMWR Recomm Rep 57(RR-5):1-30 quiz CE2-4

36. Hagihara Y, Ohfuji S, Watanabe K, Yamagami H, Fukushima W, Maeda K, Kamata N, Sogawa M, Shiba M, Tanigawa T, Tominaga K, Watanabe T, Fujiwara Y, Hirota Y, Arakawa T (2014) Infliximab and/or immunomodulators inhibit immune responses to trivalent influenza vaccination in adults with inflammatory bowel disease. J Crohns Colitis 8(3):223-233. https://doi.org/ 10.1016/j.crohns.2013.08.008

37. Fischer L, Gerstel PF, Poncet A, Siegrist CA, Laffitte E, Gabay C, Seebach JD, Ribi C (2015) Pneumococcal polysaccharide vaccination in adults undergoing immunosuppressive treatment for inflammatory diseases - a longitudinal study. Arthritis Res Ther 17(1):151. https://doi.org/10.1186/s13075-015-0663-9

38. Friedman MA, Winthrop KL (2017) Vaccines and diseasemodifying antirheumatic drugs: practical implications for the rheumatologist. Rheum Dis Clin N Am 43(1):1-13. https://doi. org/10.1016/j.rdc.2016.09.003

39. Perry LM, Winthrop KL, Curtis JR (2014) Vaccinations for rheumatoid arthritis. Curr Rheumatol Rep 16. https://doi.org/10.1007/ s11926-014-0431-x

40. Intongkam S, Samakarnthai P, Pakchotanon R, Narongroeknawin P, Assavatanabodee P, Chaiamnuay S (2019) Efficacy and safety of hepatitis $\mathrm{B}$ vaccination in rheumatoid arthritis patients receiving disease-modifying antirheumatic drugs and/or biologics therapy. J Clin Rheumatol 25(8):329-334. https://doi.org/10.1097/RHU. 0000000000000877 .

41. Smolen, J.S., Landewé, R.B.M., Bijlsma, J.W.J., Burmester, G.R., Dougados, M., Kerschbaumer, A., et al., (2020). EULAR recommendations for the management of rheumatoid arthritis with synthetic and biological disease-modifying antirheumatic drugs: 2019 update. Annals of the Rheumatic Diseases 79(6):685-699. https:// doi.org/10.1136/annrheumdis-2019-216655

42. Abu-Shakra M, Press J, Varsano N, Levy V, Mendelson E, Sukenik S, Buskila D (2002) Specific antibody response after influenza immunization in systemic lupus erythematosus. J Rheumatol 29(12):2555-2557

43. Park JK, Lee YJ, Bitoun S, Winthrop KL, Choi Y, Lee EB, Mariette X (2019) Interaction between B-cell activation factor and methotrexate impacts immunogenicity of seasonal influenza vaccination in patients with rheumatoid arthritis. Ann Rheum Dis 78(2):282-284. https://doi.org/10.1136/annrheumdis-2018214025

44. Subesinghe S, Bechman K, Rutherford AI, Goldblatt D, Galloway JB (2018) A systematic review and metaanalysis of antirheumatic drugs and vaccine immunogenicity in rheumatoid arthritis. $\mathrm{J}$ Rheumatol 45(6):733-744. https://doi.org/10.3899/jrheum. 170710

45. Kapetanovic MC, Kristensen L-E, Saxne T, Aktas T, Mörner A, Geborek P (2014) Impact of anti-rheumatic treatment on immunogenicity of pandemic H1N1 influenza vaccine in patients with arthritis. Arthritis Res Ther 16:R2. https://doi.org/10.1186/ar4427

46. Fomin I (2006) Vaccination against influenza in rheumatoid arthritis: the effect of disease modifying drugs, including TNF blockers. Ann Rheum Dis 65:191-194. https://doi.org/10.1136/ $\operatorname{ard} .2005 .036434$

47. Park JK, Choi Y, Winthrop KL, Song YW, Lee EB (2019) Optimal time between the last methotrexate administration and seasonal influenza vaccination in rheumatoid arthritis: post hoc analysis of a randomised clinical trial. Ann Rheum Dis 78(9): 1283-1284. https://doi.org/10.1136/annrheumdis-2019-215187 
48. Mehta P, Sanchez E, Moraitis E, Longley N, Lendrem DW, Giles IP, Chambers RC, Ciurtin C, Isaacs JD (2020) Influenza vaccination and interruption of methotrexate in adult patients in the COVID-19 era: an ongoing dilemma. Lancet Rheumatol. https:// doi.org/10.1016/s2665-9913(20)30392-1

49. Kapetanovic MC, Roseman C, Jönsson G, Truedsson L, Saxne T, Geborek P (2011) Antibody response is reduced following vaccination with 7 -valent conjugate pneumococcal vaccine in adult methotrexate-treated patients with established arthritis, but not those treated with tumor necrosis factor inhibitors. Arthritis Rheum 63(12):3723-3732. https://doi.org/10.1002/art.30580

50. Kobie JJ, Zheng B, Bryk P, Barnes M, Ritchlin CT, Tabechian DA, Anandarajah AP, Looney RJ, Thiele RG, Anolik JH, Coca A, Wei C, Rosenberg AF, Feng C, Treanor JJ, Lee FE, Sanz I (2011) Decreased influenza-specific B cell responses in rheumatoid arthritis patients treated with anti-tumor necrosis factor. Arthritis Res Ther 13(6):R209. https://doi.org/10.1186/ar3542

51. Iwamoto M, Homma S, Onishi S, Kamata $\mathrm{Y}$, Nagatani K, Yamagata Z, Minota S (2012) Low level of seroconversion after a novel influenza $\mathrm{A} / \mathrm{H} 1 \mathrm{~N} 1 / 2009$ vaccination in Japanese patients with rheumatoid arthritis in the 2009 season. Rheumatol Int 32: 3691-3694. https://doi.org/10.1007/s00296-011-2118-1

52. Franca IL, Ribeiro AC, Aikawa NE, Saad CG, Moraes JC, Goldstein-Schainberg C, Laurindo IM, Precioso AR, Ishida MA, Sartori AM, Silva CA, Bonfa E (2012) TNF blockers show distinct patterns of immune response to the pandemic influenza $A$ H1N1 vaccine in inflammatory arthritis patients. Rheumatology (Oxford) 51(11):2091-2098. https://doi.org/10.1093/ rheumatology/kes202

53. Michel M, Vincent FB, Rio S, Leon N, Marcelli C (2016) Influenza vaccination status in rheumatoid arthritis and spondyloarthritis patients receiving biologic DMARDs. Joint Bone Spine 83(2):237-238. https://doi.org/10.1016/j.jbspin. 2015.02.016.

54. Kapetanovic MC, Saxne T, Sjöholm A, Truedsson L, Jönsson G, Geborek P (2006) Influence of methotrexate, TNF blockers and prednisolone on antibody responses to pneumococcal polysaccharide vaccine in patients with rheumatoid arthritis. Rheumatology (Oxford) 45(1):106-111. https://doi.org/10.1093/rheumatology/ kei193

55. Nisar MK, Ostor AJ (2013) TNF antagonists and shingles: is vaccination advisable? Ann Rheum Dis 72(5):e1. https://doi.org/10. 1136/annrheumdis-2013-203389

56. Chioato A, Noseda E, Stevens M, Gaitatzis N, Kleinschmidt A, Picaud H (2012) Treatment with the interleukin-17A-blocking antibody secukinumab does not interfere with the efficacy of influenza and meningococcal vaccinations in healthy subjects: results of an open-label, parallel-group, Randomized Single-Center Study. Clin Vaccine Immunol 19:1597-1602. https://doi.org/10. 1128/cvi.00386-12

57. Richi P, Martín MD, de Ory F, Gutiérrez-Larraya R, Casas I, Jiménez-Díaz AM, Cava F, Muñoz-Fernandez S (2019) Secukinumab does not impair the immunogenic response to the influenza vaccine in patients. RMD Open 5(2):e001018. https:// doi.org/10.1136/rmdopen-2019-001018.

58. Furer V, Zisman D, Kaufman I, Arad U, Berman M, SarbagilMaman H, Elias M, Hadad A, Paran D, Drori Y, Friedman N, Mandelboim M, Elkayam O (2020) Immunogenicity and safety of vaccination against seasonal influenza vaccine in patients with psoriatic arthritis treated with secukinumab. Vaccine 38(4):847851. https://doi.org/10.1016/j.vaccine.2019.10.081

59. Gomez EV, Bishop JL, Jackson K, Muram TM, Phillips D (2017) Response to tetanus and pneumococcal vaccination following administration of ixekizumab in healthy participants. BioDrugs. 31(6):545-554. https://doi.org/10.1007/s40259-017-0249-y.
60. Soy M, Keser G, Atagündüz P, Tabak F, Atagündüz I, Kayhan S (2020) Cytokine storm in COVID-19: pathogenesis and overview of anti-inflammatory agents used in treatment. Clin Rheumatol 39: 2085-2094. https://doi.org/10.1007/s10067-020-05190-5

61. Mori S, Ueki Y, Hirakata N, Oribe M, Hidaka T, Oishi K (2012) Impact of tocilizumab therapy on antibody response to influenza vaccine in patients with rheumatoid arthritis. Ann Rheum Dis 71(12):2006-2010. https://doi.org/10.1136/annrheumdis-2012201950

62. Bingham CO, Rizzo W, Kivitz A, Hassanal A, Upmanyu R, Klearman M (2015) Humoral immune response to vaccines in patients with rheumatoid arthritis treated with tocilizumab: results of a randomised controlled trial (VISARA). Ann Rheum Dis 74: 818-822. https://doi.org/10.1136/annrheumdis-2013-204427

63. Tsuru T, Terao K, Murakami M, Matsutani T, Suzaki M, Amamoto T, Nakashima H, Akiyama A, Nishimoto N (2014) Immune response to influenza vaccine and pneumococcal polysaccharide vaccine under IL-6 signal inhibition therapy with tocilizumab. Mod Rheumatol 24(3):511-516. https://doi.org/10. 3109/14397595.2013.843743

64. Alten R, Bingham CO 3rd, Cohen SB, Curtis JR, Kelly S, Wong D, Genovese MC (2016) Antibody response to pneumococcal and influenza vaccination in patients with rheumatoid arthritis receiving abatacept. BMC Musculoskelet Disord 26(17):231. https://doi. org/10.1186/s12891-016-1082-z.

65. Ter Haar N, Lachmann H, Özen S, Woo P, Uziel Y, Modesto C, Koné-Paut I, Cantarini L, Insalaco A, Neven B, Hofer M, Rigante D, Al-Mayouf S, Touitou I, Gallizzi R, Papadopoulou-Alataki E, Martino S, Kuemmerle-Deschner J, Obici L, Iagaru N, Simon A, Nielsen S, Martini A, Ruperto N, Gattorno M, Frenkel J (2013) Treatment of autoinflammatory diseases: results from the Eurofever Registry and a literature review. Ann Rheum Dis 72: 678-685. https://doi.org/10.1136/annrheumdis-2011-201268

66. Furer V, Rondaan C, Heijstek M, Van Assen S, Bijl M, AgmonLevin N, Breedveld FC, et al. (2019). Incidence and prevalence of vaccine preventable infections in adult patients with autoimmune inflammatory rheumatic diseases (AIIRD): a systemic literature review informing the 2019 update of the EULAR recommendations for vaccination in adult patients wit. RMD Open 5, e001041. https://doi.org/10.1136/rmdopen-2019-001041

67. Van Assen S, Agmon-Levin N, Elkayam O, Cervera R, Doran MF, Dougados M, Emery P, Geborek P, Ioannidis JPA, Jayne DRW, Kallenberg CGM, Müller-Ladner U, Shoenfeld Y, Stojanovich L, Valesini G, Wulffraat NM, Bijl M (2011) EULAR recommendations for vaccination in adult patients with autoimmune inflammatory rheumatic diseases. Ann Rheum Dis 70:414 422. https://doi.org/10.1136/ard.2010.137216

68. Heijstek MW, Ott de Bruin LM, Bijl M, Borrow R, van der Klis F, Koné-Paut I, Fasth A, Minden K, Ravelli A, Abinun M, Pileggi GS, Borte M, Wulffraat NM; EULAR (2011). EULAR recommendations for vaccination in paediatric patients with rheumatic diseases. Ann Rheum Dis 70(10):1704-1712. https://doi.org/10. 1136/ard.2011.150193

69. Ter Haar NM, Oswald M, Jeyaratnam J, Anton J, Barron KS, Brogan PA, Cantarini L, Galeotti C, Grateau G, Hentgen V, Hofer M, Kallinich T, Kone-Paut I, Lachmann HJ, Ozdogan H, Ozen S, Russo R, Simon A, Uziel Y, Wouters C, Feldman BM, Vastert SJ, Wulffraat NM, Benseler SM, Frenkel J, Gattorno M, Kuemmerle-Deschner JB (2015) Recommendations for the management of autoinflammatory diseases. Ann Rheum Dis 74(9): 1636-1644. https://doi.org/10.1136/annrheumdis-2015-207546

70. Jeyaratnam J, Ter Haar NM, Lachmann HJ, Kasapcopur O, Ombrello AK, Rigante D, Dedeoglu F, Baris EH, Vastert SJ, Wulffraat NM, Frenkel J (2018) The safety of live-attenuated vaccines in patients using IL-1 or IL-6 blockade: an international 
survey. Pediatr Rheumatol 16. https://doi.org/10.1186/s12969018-0235-Z

71. Chioato A, Noseda E, Felix SD, Stevens M, Del Giudice G, Fitoussi S, Kleinschmidt A (2010) Influenza and meningococcal vaccinations are effective in healthy subjects treated with the interleukin-1 $\beta$-blocking antibody canakinumab: results of an open-label, parallel group, randomized, single-center study. Clin Vaccine Immunol 17:1952-1957. https://doi.org/10.1128/cvi. 00175-10

72. Brogan P, Hofer M, Kuemmerle-Deschner J, Lauwerys B, Speziale A, Abrams K, Leon K, Wei X, Laxer R (2015) Efficacy, safety, and post-vaccination antibody titer data in children with CAPS treated with canakinumab. Pediatr Rheumatol 13:P1. https://doi.org/10.1186/1546-0096-13-s1-p1

73. Quartier P, Allantaz F, Cimaz R, Pillet P, Messiaen C, Bardin C, Bossuyt X, Boutten A, Bienvenu J, Duquesne A, Richer O, Chaussabel D, Mogenet A, Banchereau J, Treluyer J-M, Landais P, Pascual V (2011) A multicentre, randomised, double-blind, placebo-controlled trial with the interleukin-1 receptor antagonist anakinra in patients with systemic-onset juvenile idiopathic arthritis (ANAJIS trial). Ann Rheum Dis 70:747-754. https://doi.org/ 10.1136/ard.2010.134254

74. Heijstek MW, Kamphuis S, Armbrust W, Swart J, Gorter S, de Vries LD, Smits GP, van Gageldonk PG, Berbers GA, Wulffraat NM (2013) Effects of the live attenuated measles-mumps-rubella booster vaccination on disease activity in patients with juvenile idiopathic arthritis: a randomized trial. JAMA 309(23):24492456. https://doi.org/10.1001/jama.2013.6768

75. Kuemmerle-Deschner JB, Hachulla E, Cartwright R, Hawkins PN, Tran TA, Bader-Meunier B, Hoyer J, Gattorno M, Gul A, Smith J, Leslie KS, Jiménez S, Morell-Dubois S, Davis N, Patel N, Widmer A, Preiss R, Lachmann HJ (2011) Two-year results from an open-label, multicentre, phase III study evaluating the safety and efficacy of canakinumab in patients with cryopyrinassociated periodic syndrome across different severity phenotypes. Ann Rheum Dis 70(12):2095-2102. https://doi.org/10. 1136/ard.2011.152728.

76. Jaeger VK, Hoffman HM, van der Poll T, Tilson H, Seibert J, Speziale A, Junge G, Franke K, Vritzali E, Hawkins PN, Kuemmerle-Deschner J, Walker UA (2017) Safety of vaccinations in patients with cryopyrin-associated periodic syndromes: a prospective registry based study. Rheumatology (Oxford) 56(9): 1484-1491. https://doi.org/10.1093/rheumatology/kex 185 .

77. Richi P, Alonso O, Martín MD, González-Hombrado L, Navío T, Salido M, Llorente J, Andreu-Vázquez C, García-Fernández C, Jiménez-Diaz A, Lojo L, Cebrián L, Thuissard-Vasallo I, Martínez de Aramayona MJ, Cobo T, García-Castro M, Castro P, Fernández-Castro M, Illera Ó, Steiner M, Muñoz-Fernández S (2020) Evaluation of the immune response to hepatitis B vaccine in patients on biological therapy: results of the RIER cohort study. Clin Rheumatol 39(9):2751-2756. https://doi.org/10.1007/ s10067-020-05042-2

78. Van Assen S, Holvast A, Benne CA, Posthumus MD, Van Leeuwen MA, Voskuyl AE, Blom M, Risselada AP, De Haan A, Westra J, Kallenberg CGM, Bijl M (2010) Humoral responses after influenza vaccination are severely reduced in patients with rheumatoid arthritis treated with rituximab. Arthritis Rheum 62: 75-81. https://doi.org/10.1002/art.25033

79. Hua C, Barnetche T, Combe B, Morel J (2013) Effect of methotrexate, antitumor necrosis factor $\alpha$, and rituximab on the immune response to influenza and pneumococcal vaccines in patients with rheumatoid arthritis:a systematic review and meta-analysis. Arthritis Care Res 66:1016-1026

80. Baker D, Roberts CAK, Pryce G, Kang AS, Marta M, Reyes S, Schmierer K, Giovannoni G, Amor S (2020) COVID-19 vaccinereadiness for anti-CD20-depleting therapy in autoimmune diseases. Clin Exp Immunol 202:149-161. https://doi.org/10. 1111/cei.13495

81. Crnkic Kapetanovic M, Saxne T, Jonsson G, Truedsson L, Geborek P (2013) Rituximab and abatacept but not tocilizumab impair antibody response to pneumococcal conjugate vaccine in patients with rheumatoid arthritis. Arthritis Res Ther 15(5):R171

82. Oren S, Mandelboim M, Braun-Moscovici Y, Paran D, Ablin J, Litinsky I, Comaneshter D, Levartovsky D, Mendelson E, Azar R, Wigler I, Balbir-Gurman A, Caspi D, Elkayam O (2008) Vaccination against influenza in patients with rheumatoid arthritis: the effect of rituximab on the humoral response. Ann Rheum Dis 67:937-941. https://doi.org/10.1136/ard.2007.077461

83. Arad U, Tzadok S, Amir S et al (2011) The cellular immune response to influenza vaccination is preserved in rheumatoid arthritis patients treated with rituximab. Vaccine. 29(8):1643-1648

84. Rehnberg M, Brisslert M, Amu S, Zendjanchi K, Håwi G, Bokarewa MI (2010) Vaccination response to protein and carbohydrate antigens in patients with rheumatoid arthritis after rituximab treatment. Arthritis Res Ther 12:R111. https://doi.org/10. $1186 /$ ar3047

85. Westra J, Van Assen S, Wilting KR, Land J, Horst G, De Haan A, Bijl M (2014) Rituximab impairs immunoglobulin (Ig)M and IgG (subclass) responses after influenza vaccination in rheumatoid arthritis patients. Clin Exp Immunol 178:40-47. https://doi.org/10. 1111/cei.12390

86. Eisenberg RA, Jawad AF, Boyer J, Maurer K, Mcdonald K, Prak ETL, Sullivan KE (2013) Rituximab-treated patients have a poor response to influenza vaccination. J Clin Immunol 33:388-396. https://doi.org/10.1007/s10875-012-9813-x

87. Gelinck LB, van der Bijl AE, Beyer WE, Visser LG, Huizinga TW, van Hogezand RA et al (2008) The effect of anti-tumour necrosis factor alpha treatment on the antibody response to influenza vaccination. Ann Rheum Dis 67(5):713-716. https://doi.org/ 10.1136/ard.2007.077552.

88. Gabay C, Bel M, Combescure C, Ribi C, Meier S, Posfay-Barbe K, Grillet S, Seebach JD, Kaiser L, Wunderli W, Guerne PA, Siegrist CA, H1N1 Study Group (2011) Impact of synthetic and biologic disease-modifying antirheumatic drugs on antibody responses to the AS03-adjuvanted pandemic influenza vaccine: a prospective, open-label, parallel-cohort, single-center study. Arthritis Rheum 63(6):1486-1496. https://doi.org/10.1002/art. 30325

89. Bingham CO 3rd, Looney RJ, Deodhar A, Halsey N, Greenwald M, Codding C, Trzaskoma B, Martin F, Agarwal S, Kelman A (2010) Immunization responses in rheumatoid arthritis patients treated with rituximab: results from a controlled clinical trial. Arthritis Rheum 62(1):64-74. https://doi.org/10.1002/art.25034. XXX

90. Bühler S, Eperon G, Ribi C, Kyburz D, Van G, Visser L, Siegrist C, Hat C (2015) Vaccination recommendations for adult patients with autoimmune inflammatory rheumatic diseases. Swiss Med Wkly. https://doi.org/10.4414/smw.2015.14159

91. Bijl M, Agmon-Levin N, Dayer JM, Israeli E, Gatto M, Shoenfeld Y (2012) Vaccination of patients with auto-immune inflammatory rheumatic diseases requires careful benefit-risk assessment. Autoimmun Rev 11(8):572-576. https://doi.org/10.1016/j.autrev. 2011.10.015.

92. Gelinck LB, Teng YK, Rimmelzwaan GF, van den Bemt BJ, Kroon FP, van Laar JM. (2007) Poor serological responses upon influenza vaccination in patients with rheumatoid arthritis treated with rituximab. Ann Rheum Dis 66(10):1402-1403. https://doi. org/10.1136/ard.2007.071878.

93. Crnkic Kapetanovic M, Saxne T, Jönsson G, Truedsson L, Geborek P (2013) Rituximab and abatacept but not tocilizumab impair antibody response to pneumococcal conjugate vaccine in 
patients with rheumatoid arthritis. Arthritis Res Ther 15(5):R171. https://doi.org/10.1186/ar4358

94. Rehnberg M, Brisslert M, Amu S, Zendjanchi K, Håwi G, Bokarewa MI (2010) Vaccination response to protein and carbohydrate antigens in patients with rheumatoid arthritis after rituximab treatment. Arthritis Res Ther 12(3):R111. https://doi.org/10. 1186/ar3047

95. Winthrop KL, Silverfield J, Racewicz A, Neal J, Lee EB, Hrycaj P, Gomez-Reino J, Soma K, Mebus C, Wilkinson B, Hodge J, Fan $\mathrm{H}$, Wang T, Bingham CO 3rd. (2016) The effect of tofacitinib on pneumococcal and influenza vaccine responses in rheumatoid arthritis. Ann Rheum Dis 75(4):687-695. https://doi.org/10.1136/ annrheumdis-2014-207191

96. Shimabukuro T, Nair N (2021) Allergic reactions including anaphylaxis after receipt of the first dose of Pfizer-BioNTech COVID-19 vaccine. JAMA. https://doi.org/10.1001/jama.2021. 0600
97. Voysey M, Clemens SAC, Madhi SA, Weckx LY, Folegatti PM, Aley PK, Angus B et al (2021) Safety and efficacy of the ChAdOx1 nCoV-19 vaccine (AZD1222) against SARS-CoV-2: an interim analysis of four randomised controlled trials in Brazil, South Africa, and the UK. Lancet 397:99-111. https://doi.org/10. 1016/s0140-6736(20)32661-1

98. https://www.rheumatology.org.uk/practice-quality/covid-19guidance; last accessed 12.01.2021.

99. https://dgrh.de/Start/Wissenschaft/Forschung/COVID-19/ Impfung-gegen-SARS-CoV2.html) last accessed 12.01.2021.

100. https://www.rheumatology.org/About-Us/Newsroom/PressReleases/ID/1138

Publisher's note Springer Nature remains neutral with regard to jurisdictional claims in published maps and institutional affiliations. 